\title{
Continuation versus discontinuation of treatment for severe dementia: randomized, pragmatic, open-label, clinical trial to evaluate the efficacy of continuing drug treatment in patients with severe dementia (STOP-DEM)
}

Aina Soler ${ }^{1,2^{*}}$, Guillem Amer ${ }^{3}$, Alicia Leiva ${ }^{1,2}$, Joana Ripoll ${ }^{1,2}$, María Angeles Llorente $^{5}$, Alfonso Leiva ${ }^{1,2}$, Joana Maria Taltavull ${ }^{1,2}$, Rosa Molina ${ }^{4}$ and Joan Llobera ${ }^{1,2}$

\begin{abstract}
Background: Previous observational studies and clinical trials have shown that cholinesterase inhibitors (with or without memantine) provide benefit for patients with mild-to-moderate Alzheimer's disease. However, the impact of treatment continuation after progression to severe disease is unknown. The main aim of this study is to evaluate the effect and safety of continuing treatment with ChEls (with or without memantine) for patients with severe dementia.

Methods: This randomized, pragmatic, open-label clinical trial with blinded evaluators will evaluate the efficacy of continuing drug treatment in patients with advanced dementia. A total of 302 community-dwelling patients with severe dementia, Alzheimer's disease, with or without a coexisting diagnosis of vascular dementia, and a score of 10 or less on the Mini-Mental State Examination who received previous treatment with a cholinesterase inhibitor (with or without memantine) for at least 3 months, will be randomized to continue or discontinue drug treatment. Follow-up will be 12 months or until the primary endpoint is achieved. The primary endpoint is entry into institutional care and progression of disability, defined as a loss of 2 of 4 basic functions, or 6 of 11 instrumental functions, according to the Bristol Activities of Daily Living Scale at 12 months. The secondary outcomes are patient changes in functional and cognitive state, quality of life, and caregiver burden.
\end{abstract}

Discussion: We expect that the results of our study will allow to identify if there is clinical relevant impact for patients and caregivers between maintaining or halting pharmacological treatment.

Trial registration: The study was prospectively registered in the REec (2017-000042-22) on May 112017 and ID ISRCTN12134230 on February 252019.

Keywords: Dementia, Cholinesterase inhibitors, Deprescription, Randomized controlled trial

\footnotetext{
* Correspondence: ainasoler@ibsalut.caib.es

${ }^{1}$ Primary Care Research Unit of Mallorca, Baleares Health Services-lbSalut,

Palma, Spain

${ }^{2}$ Instituto de Investigación Sanitaria de Palma, Palma, Spain

Full list of author information is available at the end of the article
}

(c) The Author(s). 2019 Open Access This article is distributed under the terms of the Creative Commons Attribution 4.0 International License (http://creativecommons.org/licenses/by/4.0/), which permits unrestricted use, distribution, and reproduction in any medium, provided you give appropriate credit to the original author(s) and the source, provide a link to the Creative Commons license, and indicate if changes were made. The Creative Commons Public Domain Dedication waiver (http://creativecommons.org/publicdomain/zero/1.0/) applies to the data made available in this article, unless otherwise stated. 


\section{Background}

Dementia is a chronic progressive mental disorder that adversely affects higher cortical functions, including cognition and behavior leading up to disability and dependence in daily life activities. It has become a major public health concern because of its increasing prevalence, chronicity, burden for caregivers, and the high personal and financial costs needed for care. Age is the main risk factor for dementia, and its prevalence in Spain is 5 to $14.9 \%$ in people over 65 years-old, and 9 to $17.2 \%$ in people over 70 years-old [1]. Thus, Alzheimer's disease (AD) and other dementias are currently considered a major public health concern. A recent forecast predicted 14 million cases in Europe by 2050 [2]. In Spain, up to $11 \%$ of deaths overall are related to dementias, and about one-third of people older than 85 years die from dementia [3].

There are no cures for AD, but most guidelines recommend pharmacological treatment to alleviate symptoms and might delay disease progression. Cholinesterase inhibitors (ChEI; donepezil, galantamine, rivastigmine, and tacrine) are approved for managing mild to moderate AD. Memantine [an N-methyl D-aspartate (NMDA) receptor antagonist] is approved for treatment of moderate to severe dementia of the Alzheimer's type but these drugs are also given off-label for other types of dementia (vascular and mixed dementias), and severe dementia. The pharmacotherapeutic agents available to treat problems associated with dementias have different levels of evidence to support their efficacy. ChEIs produce small, short-term improvements in the cognitive function of patients with mild to moderate dementia, which can result in statistically significant changes, but only marginally significant clinical improvements in cognition and global assessment scores. Moreover, these drugs provide minimal benefits for those who have severe disease, are receiving long-term treatment, and who are elderly [4]. There is very limited evidence to guide the difficult decision about whether to continue or discontinue treatment as disease progresses.

ChEIs can also cause adverse effects, and these increase with ChEI dose. Adverse effects are also 2-fold greater in those over 85 years-old than in younger patients. In particular, cholinergic stimulation leads to a 2- to 5 -fold increased risk for gastrointestinal, neurological, and cardiovascular adverse effects, the most serious being weight loss, debility, and syncope [5].

Some clinical trials have evaluated the efficacy and safety of different drug treatments for patients with dementia. The first of these was the AD2000 study [6]. These authors used a double-blind procedure to examine the effect of the dose and duration of donepezil treatment on disability, dependency, psychological factors and behavioral symptoms of dementia, welfare of the caregiver, and delay in institutionalization. They recruited 565 patients with mild or moderate AD (in the initial phase) and randomized them to receive donepezil ( 5 or $10 \mathrm{mg}$ daily) or placebo for 12 weeks. The 486 patients who completed this phase of the study were then randomized again to receive donepezil or placebo. The main outcome measures were institutionalization and progression of disability, assessed by the Bristol activities of daily life scale (BADLS). After 3 years, the effects of donepezil and placebo were similar for institutionalization ( $42 \%$ vs. $44 \%$ ) and progression of disability (58\% vs. $59 \%$ ). The treatment groups had a relative risk (RR) of institutionalization of 0.97 (95\% confidence interval [CI]: $0.72-1.30, p=0.8)$, an $\mathrm{RR}$ of progression of disability or institutionalization of 0.96 (95\% CI, $0.74-$ $1.24, p=0.7)$. The two groups also had no differences in the symptoms of psychological and behavioral dementia (SPBD), costs of formal care, adverse events (AE), or mortality. It is important to highlight that these results differ from the clinical trials performed by the drug manufacturer, which examined patients in usual practice conditions, and included patients with vascular dementia (VD) and/or mixed dementia.

The DOMINO-AD clinical trial [7] evaluated the effectiveness of ChEIs (with or without memantine) in 295 patients with moderate-to-severe $\mathrm{AD}$. All patients who received prior treatment with donepezil (minimum of 3 months) were randomly assigned to a group that continued or discontinued this drug (with or without memantine) for 1 year. Relative to those who stopped donepezil, patients who continued donepezil experienced less mental deterioration, based on the Mini-Mental State Examination (MMSE, $p<0.001)$ and the BADLS $(p<0.001)$ after 1 year. In addition, patients who took memantine scored better on both tests than those who did not (MMSE: $p<0.001$; BADLS: $p=0.02$ ). However, treatment with both drugs provided no greater benefit than donepezil alone. These results support the continued use of donepezil in patients with moderate-to-severe $\mathrm{AD}$, based on evaluation of its functional benefits at 12 months [8].

A secondary outcome of this study was to evaluate whether continuation of pharmacological treatment would also delay time to institutionalization in this patients [7]. Although more than half of the patients entered a nursing home over the follow up period, a post-hoc analysis showed that continuation of a drug treatment delayed nursing home placement in patients with AD. Patients who continued on drug treatment had lower risk of entering a nursing home within the first year after intervention [hazard ratio (HR) 2.09 (95\% confidence interval 1.29 to 3.39)], however there was no difference between continuation or discontinuation in the subsequent 3 years [HR 0.89 (0.58 to 1.35)].

A recently published meta-analysis of randomized controlled trials examined the effects of ChEI discontinuation in patients with $\mathrm{AD}$. As previous studies, the 
results suggested that ChEI discontinuation may be associated with a statistically significant deterioration in cognition and neuropsychiatric symptoms but, again only one study included patients with advanced dementia $(\mathrm{MMSE}<10)[9]$.

Importantly, these studies only examined patients with $\mathrm{AD}$ and very few studies evaluated the efficacy of these drugs in patients with other types of dementia or severe dementia. Thus, the specific aim of the present study of patients with advanced dementia is to compare the effect of maintaining treatment with a ChEI (with or without memantine) vs. discontinuing drug treatment on the time to institutionalization and/or progression of disability (defined as a loss of 2 of 4 basic functions, or 6 of 11 instrumental functions, according to the BADLS) at 12 months.

Even if there is considerable uncertainty on the benefits and harms of both prescribing and deprescribing ChEI, most guidelines recommend individualized treatment decisions depending on patient and caregiver or family experiences. The only relevant domains identified by most authors are a lack of response or a loss of effectiveness, which can be difficult to evaluate in patients with advanced dementia [10, 11]. Well-designed, long-term studies of discontinuation have not been conducted; such evidence is needed to provide a scientific basis for practice guidelines [12].

The main aim of this study is to evaluate the effect and safety of continuing treatment with ChEIs (with or without memantine) for patients with severe dementia.

\section{Methods}

Design

This study of patients with advanced dementia is a clinical, pragmatic, multicenter, open trial with blinded assessors and a parallel randomized design that will evaluate the effect of maintaining pharmacological treatment versus treatment withdrawal. The main outcome measures are institutionalization and/or functional disability. Table 1 summarizes the evaluations that will be used and Fig. 1 shows the schedule for enrollment, interventions, and assessments.

\section{Setting}

We will perform this study in at least in 5 health centers and 1 hospital of the Balearic Islands (Spain), with the number determined by recruitment rate.

\section{Participants \\ Inclusion criteria}

This study will include patients with advanced dementia who are living in the community and receiving treatment in a primary care setting or a hospital.

Participants must have the following criteria for enrollment:

1. Patient with dementia due to $\mathrm{AD}$, according to National Institute on Aging and Alzheimer's Association (NIA-AA) criteria [13], with or without

Table 1 Summary of visits and content

\begin{tabular}{|c|c|c|}
\hline Instrument & Assessment & Timing of assessment \\
\hline Inclusion form & Eligibility criteria & Previous to randomization \\
\hline $\begin{array}{l}\text { Sociodemographic form of patient and } \\
\text { caregiver }\end{array}$ & Sociodemographic data & Basal \\
\hline Baseline clinical data form & $\begin{array}{l}\text { Treatment for dementia } \\
\text { Diseases and concomitant treatments }\end{array}$ & Basal \\
\hline Institucionalization form & Institutionalization date & $1,3,6 \& 12$ months (study end) \\
\hline SMMSE & Cognitive assessment & $\begin{array}{l}\text { Basal, 1,3,6 \& } 12 \text { months (study } \\
\text { end) }\end{array}$ \\
\hline BADLS & Functional assessment & $\begin{array}{l}\text { Basal, 1,3,6 \& } 12 \text { months (study } \\
\text { end) }\end{array}$ \\
\hline FAST & Functional assessment & Basal \& 12 months (study end) \\
\hline QUALID & Advanced dementia quality of life & $\begin{array}{l}\text { Basal, 1,3,6 \& } 12 \text { months (study } \\
\text { end) }\end{array}$ \\
\hline EQ-5D & Quality of life related to health & Basal \& 12 months (study end) \\
\hline NPI-Q & $\begin{array}{l}\text { Psychological and behavioral symptoms associated to } \\
\text { dementia }\end{array}$ & $\begin{array}{l}\text { Basal, 1,3,6 \& } 12 \text { months (study } \\
\text { end) }\end{array}$ \\
\hline Zarit Scale & Caregiver overload & $\begin{array}{l}\text { Basal, 1,3,6 \& } 12 \text { months (study } \\
\text { end) }\end{array}$ \\
\hline CGIC & Clinical improvement impression & 12 months (study end) \\
\hline RUD Lite & Use of health resources in dementia & 12 months (study end) \\
\hline Adverse effects forms & Safety, adverse effects and mortality & $1,3,6 \& 12$ months (study end) \\
\hline
\end{tabular}




\begin{tabular}{|c|c|c|c|c|c|c|c|}
\hline \multirow[b]{3}{*}{ TIMEPOINT** } & \multirow{3}{*}{$\begin{array}{c}\text { Enrolment } \\
-t_{1} \\
\end{array}$} & \multicolumn{6}{|c|}{ STUDY PERIOD } \\
\hline & & \multirow{2}{*}{$\begin{array}{c}\text { Allocation } \\
0 \\
\end{array}$} & \multicolumn{4}{|c|}{ Post-allocation } & \multirow{2}{*}{$\begin{array}{l}\text { Close-out } \\
12 \text { months }\end{array}$} \\
\hline & & & $\begin{array}{c}1 \\
\text { month }\end{array}$ & $\begin{array}{c}3 \\
\text { month }\end{array}$ & $\begin{array}{c}6 \\
\text { month }\end{array}$ & $\begin{array}{c}1 \\
\text { month }\end{array}$ & \\
\hline \multicolumn{8}{|l|}{ ENROLMENT: } \\
\hline \multirow{4}{*}{$\begin{array}{r}\text { Eligibility screen } \\
\text { Informed consent } \\
\text { Allocation } \\
\text { Monitor adherence } \\
\end{array}$} & $\mathrm{X}$ & & & & & & \\
\hline & $x$ & & & & & & \\
\hline & & $\mathrm{x}$ & & & & & \\
\hline & & & & & & & $\mathrm{x}$ \\
\hline \multicolumn{8}{|l|}{ INTERVENTIONS: } \\
\hline \multicolumn{8}{|l|}{$\begin{array}{l}\text { Continue antidementia } \\
\text { treatment (ChEI and/or }\end{array}$} \\
\hline \multicolumn{8}{|l|}{$\begin{array}{r}\text { Stop antidementia } \\
\text { treatment (ChEl and/or } \\
\text { memantine }\end{array}$} \\
\hline \multicolumn{8}{|l|}{ ASSESSMENTS: } \\
\hline \multicolumn{8}{|l|}{$\begin{array}{r}\text { Sociodemographic data } \\
\text { form }\end{array}$} \\
\hline $\begin{array}{r}\text { Baseline clinical data } \\
\text { form }\end{array}$ & $x$ & & $x$ & $x$ & $x$ & $x$ & $x$ \\
\hline \multicolumn{8}{|l|}{ Primary outcome } \\
\hline $\begin{array}{r}\text { Entry to institutional care } \\
\text { and/or progression of } \\
\text { disability, defined } \\
\text { byBALDs }\end{array}$ & $x$ & & $x$ & $x$ & $x$ & $x$ & $x$ \\
\hline \multicolumn{8}{|l|}{ Secondary outcomes } \\
\hline SMMSE & $x$ & & $x$ & $x$ & $x$ & $\mathrm{x}$ & $x$ \\
\hline QUALID & $x$ & & & & & & $x$ \\
\hline FAST & $\mathrm{x}$ & & & & & & $\mathrm{x}$ \\
\hline EQ-5D & $\mathrm{X}$ & & & & & & $\mathrm{X}$ \\
\hline NPI-Q & $x$ & & $\mathrm{X}$ & $x$ & $\mathrm{x}$ & $\mathrm{x}$ & $\mathrm{X}$ \\
\hline CGIC & & & & & & & $\mathrm{X}$ \\
\hline Zarit Scale & $x$ & & $\mathrm{x}$ & $\mathrm{x}$ & $\mathrm{x}$ & $\mathrm{x}$ & $\mathrm{x}$ \\
\hline RUD Lite & & & & & & & $\mathrm{x}$ \\
\hline Adverse events & & & $\mathrm{x}$ & $\mathrm{x}$ & $\mathrm{X}$ & $\mathrm{x}$ & $\mathrm{x}$ \\
\hline
\end{tabular}

Fig. 1 Schedule of enrolment, interventions, and assessments

small vessel subcortical vascular disease Fazekas

1 or 2 , [14].

2. Advanced dementia (MMSE $\leq 10)$.

3. Use of drugs for dementia (a ChEI and/or memantine) in stable dose for 6 months or more.

4. Completion of informed consent agreement by the legal caregiver and the patient when appropriate.

5. Patients without clinical changes of dementia or acute decompensation of concomitant systemic diseases and stable in their pharmacological treatment for dementia or other diseases in the last 3 months

\section{Exclusion criteria}

Participants who exhibit any of the following will be excluded:
1. Patients with non-AD suspected pathology as the main cause of the dementia.

2. Life expectancy less than the follow-up duration of the study.

3. On a waiting list for interventions or treatments that require hospitalization.

4. Participating in another clinical trial.

\section{Randomization}

A sequence of random numbers will be generated using the Epidat 3.1 program, and used for allocation to each of the two arms. After verification of patient eligibility, the recruiting researchers will make a telephone call to the research unit of the Primary Care Management to determine the group assignment. This allocation will occur after identification of the patient through an algorithm that assigns each patient to the control or 
intervention group using stratified block randomization. The two groups will be matched for mean durations of treatment with drugs for dementia prior to study onset (6 to 12 months vs. more than 12 months) and age (younger than 74 vs. 75 years or more). The randomization process will be recorded by collecting data from the code request date, patient identification code, and assigned treatment arm. The investigator who approves patient eligibility and requests the randomization will be different from the one who makes evaluations at the study visits. The main and secondary objectives of the study will be evaluated by health professionals who are not on the research team and who will remain blinded to group allocation. The person performing the statistical analysis will also be blinded to group allocation.

\section{Sample size}

The total sample size for the primary objective, with a statistical power of $80 \%$, an alpha error of $5 \%$, and a $1: 1$ ratio of subjects in the two groups, is 251 patients. The assumptions for this calculation are: (i) the incidence of the main outcome measure (time to institutionalization and/or progression of the disability, defined as a loss of 2 of 4 basic functions, or 6 of 11 instrumental functions on the BADLS) is $25 \%$ at 12 months; (ii) the minimum HR for detection of a significant difference is 2.09; and (iii) the correlation between the studied variables is 0.002 . Based on an assumed loss rate of $20 \%$ per year, at least 302 patients will be enrolled.

\section{Recruitment}

Potential participants will be identified from the billing records of the Pharmacy of the Health Service of the Balearic Islands and the Neurology Service of the Hospital Son Espases from the previous year. After study onset, the list will be updated every 3 months to identify new candidates. Primary care health centers will be provided with a list of patients receiving treatment with drugs for dementia, and the recruitment will be based on review of their clinical histories. Billing information for 2015 in the Balearic Islands indicated there were 4169 patients over 75 years-old who received treatment with a drug for dementia for 3 months or more. We anticipate we may experience some difficulties in the recruitment due to the fact that the general practitioners participating in this study would be expected to discontinue a drug that was initially prescribed in the hospital setting, mostly by neurologists. Study visits will be performed whether at health care centers or at home to promote participant retention.

\section{Intervention}

The intervention will be continuation or cessation of pharmacological treatment. This intervention will not require phased withdrawal, or any additional follow-up to assure patient safety. Adherence will be monitored through indirect adherence addressed by assessment of acquisition and possession of medication. This method is suitable to follow adherence in chronic treatment and when medication does not require frequent dosage changes [15].

\section{Primary outcomes}

The main outcome measurement will be time to institutionalization and/or progression of disability (defined as a loss of 2 of 4 basic functions, or 6 of 11 instrumental functions using the BADLS). This scale was constructed as a functional assessment of patients with dementia who are living in the community. It is a simple scale that rates 20 basic and instrumental activities of daily life. Each item has 4 answers that evaluate the functional capacity. The total score varies from 0 (totally independent) to 60 (totally dependent) [16]. It is administered by health professional, has good inter- and intra-observer reproducibility, and good correlation with the Severe Mini-Mental State Examination (SMMSE) [17]. Data on the time to institutionalization will be collected by interview with the caregiver and/or review of the clinical history [18].

\section{Secondary outcomes \\ Functional assessment}

Functional Assessment (FAST) scale will be used to assess daily life activities by examining functional loss in 16 categories that are related to self-care in patients with $\mathrm{AD}$. The FAST scale is widely used in clinical practice as a tool to grade functional difficulties and monitor changes of patients over time [19].

\section{Cognitive assessment}

The SMMSE is a brief instrument used for rapid assessments, and does not require any special materials for administration. Thus, it can be used by different types of health care professionals to assess the cognitive status of patients This scale has 30 items that evaluate aspects of cognitive functions that remain somewhat preserved in patients with advanced AD: overlearned information, simple visual-spatial functions, executive functions, basic language functions, and simple semantic fluency [20].

\section{Quality of life}

The Quality of Life in Late-Stage Dementia (QUALID) scale collects information provided by the caregiver, based on repeated observations of the patient's behavior during the previous week. It has 11 items that assess observable behaviors, which are indicative of the caregiver's individual experience regarding the patient's quality of life. These include subjective and affective states of the patient during daily life (smiling, crying, or seeming sad, 
annoying, irritable, or calm) and comfort or discomfort during basic activities of daily life from the social perspective (enjoyment of eating, touching, or interacting with others) [21].

The EuroQol five dimension (EQ-5D) scale measures self-perceived health, and incorporates individually perceived health status and is a recommended tool for use in cost-utility analyses. It consists of 2 parts: a descriptive section, determined in five dimensions, and an evaluation section, which uses a visual analog scale (VAS). The five dimensions of the descriptive section are: mobility, self-care, habitual activities, pain/discomfort, and anxiety/ depression. In the evaluation section, the patient scores his/her health from 0 to 100 using a VAS [22].

\section{Behavioral and psychological symptoms of dementia} The Neuropsychiatric Inventory-Questionnaire (NPI-Q) is administered to caregivers, who evaluate 12 aspects of the severity of symptoms in a patient. It is shorter than the NPI, and can be self-administered [23].

\section{Clinical impression}

The Clinical Global Impression of Change (CGIC) is a global classification of all domains of patient's current disease, relative to the initial state. The score ranges from 1 (much better) to 7 (much worse), with 4 indicating no change. The doctor performs this evaluation at both time points, with contributions from family members and caregivers.

\section{Cost-effectiveness}

A cost-effectiveness analysis will be based on data collected from the Resource Utilization in Dementia (RUD) Lite scale, review of clinical histories, and costs of the drugs. Cost-effectiveness will be expressed in terms of quality-adjusted life years (QALY). The RUD Lite scale evaluates factors related to the direct and indirect costs of social and health care in patients with dementia. It determines the working status of the main caregiver, time spent helping the patient in the realization of basic and instrumental activities of daily life, lost work hours, consumption of drugs, and number of visits with the patient to social and health care services [24].

\section{Caregiver overload}

The Zarit scale is an instrument that quantifies the extent of "overload" experienced by caregivers of dependent people. It consists of a list of 22 items that describe how caregivers feel. For each item, the caregiver indicates the frequency of an event, using a scale from 0 (never) to 4 (almost always) [25].
Safety

Mortality, AEs, and complications associated with dementia (emergency room visits and/or hospitalization) will be collected throughout the study.

\section{Independent variables}

The main independent variable is membership in the intervention group or control group.

\section{Independent variables}

The additional independent variables are:

a) Socio-demographic characteristics (age, sex, marital status, having a formal or informal caregiver).b) Type of previous pharmacological treatment for dementia.c) Duration of previous treatment (3 to 6 months vs. more than 6 months).

\section{Statistical analysis}

\section{Descriptive analysis, labeling, and filtering of data}

Assessment of atypical values and outliers, detection and labeling of lost and/or non-applicable values, and the distribution of variables will be assessed using normality tests and scatter plots.

\section{Baseline comparative analysis}

Comparison of the socio-demographic characteristics of the two groups will use Student's $t$-test or the Chi-square test (where appropriate). Non-parametric tests will be used when the data have non-normal distributions.

\section{Final comparative analysis}

All analyses will be performed using the intention-to-treat principle, with a two-sided level of statistical significance of $5 \%$ and adjustment for the stratification criteria of the randomization. The main outcome variable - time to institutionalization and/or progression of disability - will be assessed using Cox regression. A sensitivity analysis will be used to analyze raw efficacy data (log-rank test), Cox regression data adjusted for non-homogeneous variables, and stratification variables. The nonparametric Mann-Whitney U test and the Chi-square test will be used for analysis of the scales used for secondary outcome measures and for analysis of safety data.

\section{Cost-effectiveness analysis}

The incremental cost-effectiveness ratio (ICER) will be calculated by dividing the difference in costs by the difference in effectiveness of the two groups. To estimate the level of uncertainty in the estimates of cost differences and the ICER, bootstrapping with 500 replications of each data set will be performed. Due to the skewed distributions of costs, a correction will be performed using the bias-corrected and accelerated method. The 
estimated costs (determined by bootstrapping) and efficiency will be expressed in graphs and acceptability curves. The cost-effectiveness, net benefit, and incremental net benefit will also be calculated.

\section{Validation of the BADLS and QUALID scales}

A psychometric approach will be used to determine the extent to which the instruments measure what they intend to measure in the selected sample, to assure they reach minimum conditions of validity and reliability. The properties to be examined are: (i) viability/acceptability of the data (percentage of lost data, range of observed and possible scores, measures of central tendency and dispersion, ground and ceiling effects, asymmetry); (ii) reliability (internal consistency using Cronbach's alpha coefficient, coefficient of homogeneity of the items and correlations between items, test-retest reliability using the correlation coefficient); (iii) validity (discriminative validity using Student's $t$-test, ANOVA, Mann-Whitney $U$ test, or Kruskal-Wallis test; convergent validity using the correlation coefficient; divergent validity using the correlation coefficient; internal validity using factor analysis and inter-domain correlations; and criterion validity using correlation coefficients); and (iv) precision of measurements using standard error of mean (standard deviation $/ \sqrt{ } \mathrm{n}$ ).

\section{Data collection, management, and analysis}

Each participant will be identified by a study number only, and the master code sheet linking names with numbers will be held securely and separately from the study data. To ensure that all information is secure, data records will only be accessible to research staff and authorized personnel. After completion of all follow-ups, the data records will be de-identified and the de-identified data will be used for statistical analysis. All resulting publications will only include aggregate data.

Data entry will be done with Opentext TeleForm, a software that automatically capture, extract data and validate from paper reported form. It enables a double data entry and range checks for data values.

\section{Monitoring}

The trial will be audited by monitor at the beginning and at the end of the study. The process will be independent from the investigators and the sponsor.

Adverse events will be reported during this trial will be collected, assessed and reported as indicated in EU directive 2001/20/EC.

\section{Discussion}

Previous studies on the efficacy of pharmacological interventions for dementia have been limited by numerous factors, such as short study duration, failure to include patients with severe $\mathrm{AD}$, inadequate reporting of adverse events, failure to use clear definitions in reporting clinical significance, inadequate evaluation of behavior and quality-of-life outcomes, and inadequate direct comparisons of different treatments. Thus, there is no consensus regarding which outcomes are most clinically relevant during different stages of dementia. Furthermore, the magnitude of a clinically relevant change may depend on whether the change is reported by the patient, the caregiver, or the clinician [26].

Previous clinical trials that evaluated the clinical efficacy of anti-dementia drugs have mainly examined patients with $\mathrm{AD}$, and excluded patients with other types of dementia. In addition, despite the high prevalence of dementia, most clinical trials that examined patients with severe dementia only enrolled small numbers of patients, with the exception of the DOMINO-AD which examined 154 patients. Most previous assessments of efficacy have focused on cognitive performance, but this may be the incorrect focus for patients with advanced dementia because it does not consider the needs of the patients and their families. For patients with moderate-to-severe dementia, there is an increasing emphasis on preserving function (i.e., activities of daily life), delaying institutionalization, and management of disruptive behaviors, all of which are burdens for the caregiver [27].

To overcome the limitations of previous studies, the main outcome measure of the present study is time to institutionalization and/or progression of disability evaluated using the BADLS [6]. Although some previous studies of patients with dementia have examined time to institutionalization, patients must often wait for admission to public centers, and its assessment is non-viable, so it has been chosen to add the assessment of the progression of the disability. Moreover, the advantages of the BADLS are that it evaluates basic and instrumental functions, it has good sensitivity for patients with advanced dementia.

We used an open clinical trial design, in which only the evaluators will be blinded. Analysis of the use of anti-dementia drugs from our region indicates that even though $45 \%$ of the drugs given to those who are more than 75 years-old are in tablet form, up to $44 \%$ of patients used other formulations to improve dosing (transdermal patches, orodispersible tablets, or oral solutions). Maintaining masking by use of placebo tablets could compromise recruitment. For this reason we used a robust main outcome measure - institutionalization and/ or functional impairment using the BADLS - with blinded evaluators. Despite the pragmatic approach of our study, many patients who have dementia due to Parkinson's disease, Lewy bodies, or multiple infarctions receive treatment with the same drugs. Thus, we excluded these individuals because their quality of life, health status, and survival does not depend only on their cognitive and 
functional status. Moreover, experts agree that treatment of dementia is complex, and the use of different pharmacological agents requires detailed observations and assessments to assess potential adverse effects [28].

The present pragmatic clinical trial, which will only assess patients with severe dementia due to $\mathrm{AD}$, with or without small vessel subcortical vascular disease and will compare the efficacy of maintaining pharmacological treatment vs. treatment cessation on the time to institutionalization and/ or functional disability. Assuming that a patient's quality of life is better at home than at a nursing home, we consider nursing home admission as an outcome measure itself, because nursing home admission is considered an event to be delayed for as long as possible, from perspectives of patients and their families $[29,30]$.

We hope that our trial will contribute to provide more evidence on whether or not deprescribing and the feasibility of the withdrawal of these drugs in patients with advanced stage of dementia.

\section{Abbreviations}

AD: Alzheimer's disease; AE: Adverse event; BADLS: Bristol Activities of daily living scale; CGIC: Clinical Global Impression of Change; ChEl: Cholinesterase inhibitor; EQ-5D: EuroQol five dimension; FAST scale: Functional Assessment scale; HR: Hazard Ratio; ICER: Incremental cost-effectiveness ratio; MMSE: MiniMental State Examination; NIA-AA: National Institute on Aging and Alzheimer's Association; NMDA: N-methyl D-aspartate; NPI-Q: Neuropsychiatric InventoryQuestionnaire; QALY: Quality-adjusted life years; QUALID: Quality of Life in LateStage Dementia; RR: Relative risk; RUD: Resource Utilization in Dementia; SMMSE: Severe Mini-Mental State Examination; SPBD: Symptoms of Psychological and Behavioral Dementia; VAS: Visual analog scale; VD: Vascular dementia

\section{Acknowledgments}

Not applicable.

\section{Funding}

This study was funded by the Ministry of Economy and Competitiveness, Carlos III Institute (grant PI16/00720). Gerencia de Atención Primaria of Mallorca is the sponsor of the study. Support was also provided by the Health Promotion and Preventive Activities-Primary Health Care Network, sustained by a Ministry of Health ISCIII-RETIC award (RD12/0005/0011) and co-financed with European Union ERDF funds. The funders had no role in the study design, data collection, analysis, decision to publish, or preparation of the manuscript.

\section{Availability of data and materials}

Data sharing is not applicable to this article as no datasets were generated or analysed during the current study.

\section{Authors' contributions}

$A S, G A, J R, A F L, A C L, M L$, and $J L$ collectively drafted the study protocol and sought funding and ethical approval. JT, RM, ACL, and JR are responsible for scale validation. JR and ACL participate in the central monitoring of data collection. AS, JR, and ACL are responsible for management of the trial, data analysis, and interpretation of the results. AS, GA, JR, ML, ACL, and JL are responsible for drafting and revision of the manuscript. JR will conduct the statistical analysis. AS is the principal investigator, will have full access to all data, and will take responsibility for the integrity of the data and the accuracy of the data analysis. All authors critically read the manuscript, made important contributions, and read and approved the final version.

\section{Ethics approval and consent to participate}

This study will follow the principles outlined in the Declaration of Helsink (with the Tokyo 2004 amendment). All legal caregivers and patient when appropriate will provide written informed consent, and will be told that participation is voluntary and can be withdrawn at any time without any negative consequences concerning current or future medical treatments. Ethical approval was provided by the Primary Care Research Commission (PI16/025), the Institutional Review Board of the Balearic Islands Health Service (CEI-IB Ref. No: PI16/720), and the Spanish Agency on Drugs and Medical Devices (Agencia Española de Medicamentos y Productos Sanitarios [AEMPS]) (EudraCT number 2017-000042-22). Approved protocol version 2.0 (02/11/ 2016).

Any protocol amendments will be notified to Institutional Review Board of the Balearic Islands Health Service and Spanish Agency on Drugs and Medical Devices.

\section{Consent for publication}

Not Applicable.

\section{Competing interests}

The authors declare that they have no competing interests.

\section{Publisher's Note}

Springer Nature remains neutral with regard to jurisdictional claims in published maps and institutional affiliations.

\section{Author details}

${ }^{1}$ Primary Care Research Unit of Mallorca, Baleares Health Services-IbSalut, Palma, Spain. ${ }^{2}$ Instituto de Investigación Sanitaria de Palma, Palma, Spain. ${ }^{3}$ Son Espases Hospital, Baleares Health Services-IbSalut, Palma, Spain. ${ }^{4}$ Manacor Hospital, Baleares Health Services-lbSalut, Mallorca, Spain. ${ }^{5}$ Son Pisa Health Care Centre, Baleares Health Services-IbSalut, Palma, Spain.

Received: 11 December 2018 Accepted: 27 March 2019

Published online: 11 April 2019

\section{References}

1. Grupo de trabajo de la Guía de Práctica Clínica sobre la atención integral a las personas con enfermedad de Alzheimer, y otras demencias. Guía de Práctica Clínica sobre la Atención Integral a las Personas con Enfermedad de Alzheimer y otras Demencias. 2010.

2. Lillo-Crespo M, Riquelme J, Macrae R, et al. Experiences of advanced dementia care in seven European countries: implications for educating the workforce. Glob Health Action. 2018;11. https://doi.org/10.1080/16549716. 2018.1478686

3. Villarejo A, Benito-León J, Trincado R, et al. Dementia-associated mortality at thirteen years in the NEDICES cohort study. J Alzheimers Dis Published Online First: 2011. https://doi.org/10.3233/JAD-2011-110443.

4. Buckley JS, Salpeter SR. A risk-benefit assessment of dementia medications: systematic review of the evidence. Drugs Aging. 2015;32:453-67. https://doi. org/10.1007/s40266-015-0266-9.

5. Kim DH, Brown RT, Ding EL, et al. Dementia medications and risk of falls, syncope, and related adverse events: meta-analysis of randomized controlled trials. J Am Geriatr Soc. 2011;59:1019-31. https://doi.org/10.1111/j. 1532-5415.2011.03450.x.

6. Courtney C, Farrell D, Gray R, et al. Long-term donepezil treatment in $\mathbf{5 6 5}$ patients with Alzheimer's disease (AD2000): randomized double-blind trial. Lancet. 2004;363:2105-15. https://doi.org/10.1016/S0140-6736(04)16499-4.

7. Howard R, McShane R, Lindesay J, et al. Nursing home placement in the donepezil and Memantine in moderate to severe Alzheimer's disease (DOMINO-AD) trial: secondary and post-hoc analyses. Lancet Neurol. 2015; 14:1171-81. https://doi.org/10.1016/S1474-4422(15)00258-6.

8. Blanco-Silvente L, Capellà D, Garre-Olmo J, Vilalta-Franch J, Castells X. Predictors of discontinuation, efficacy, and safety of memantine treatment for Alzheimer's disease: meta-analysis and meta-regression of 18 randomized clinical trials involving 5004 patients. BMC Geriatr. 2018;18(1): 168. https://doi.org/10.1186/s12877-018-0857-5.

9. O'Regan J, Lanctôt KL, Mazereeuw G, et al. Cholinesterase inhibitor discontinuation in patients with Alzheimer's disease. J Clin Psychiatry. 2015; 76:e1424-31. https://doi.org/10.4088/JCP.14r09237.

10. Reeve E, Farrell B, Thompson W, Herrmann N, Sketris I, Magin P, Chenoweth L, Gorman M, Quirke L, Bethune G, Forbes F, Hilmer S. Evidence-based Clinical Practice Guideline for Deprescribing Cholinesterase Inhibitors and Memantine: Recommendations. Sydney: The University of Sydney; 2018. The 
full guideline and supporting documents are available at: http://sydney.edu. $\mathrm{au} /$ medicine/cdpc/resources/deprescribing-guidelines.php.

11. Dementia: assessment, management and support for people living with dementia and their carers. NICE guideline. Published: 20 June 2018. Available at: nice.org.uk/guidance/ng97.

12. Renn BN, Asghar-Ali AA, Thielke S, et al. A systematic review of practice guidelines and recommendations for discontinuation of cholinesterase inhibitors in dementia. Am J Geriatr Psychiatry. 2018;26:134-47. https://doi. org/10.1016/j.jagp.2017.09.027.

13. Mckhann GM, Knopman DS, Chertkow H, et al. The diagnosis of dementia due to Alzheimer's disease: recommendations from the National Institute on Aging-Alzheimer's association workgroups on diagnostic guidelines for Alzheimer's disease. Alzheimers Dement. 2011;7:263-9. https://doi.org/10. 1016/j.jalz.2011.03.005.

14. Fazekas F, Barkhof F, Wahlund LO, et al. CT and MRI rating of white matter lesions. Cerebrovasc Dis. 2002;13(Suppl 2):31-6. https://doi.org/10.1159/ 000049147.

15. Eugene Kreys. Measurements of medication adherence: in search of a gold standard | journal of clinical pathways. J Clin Pathways. 2016;2(8):43-47. Available at: https://www.journalofclinicalpathways.com/article/ measurements-medication-adherence-search-gold-standard.

16. Bucks RS, Ashworth DL, Wilcock GK, et al. Assessment of activities of daily living in dementia: development of the Bristol activities of daily living scale. Age Ageing published online first: 1996. https://doi.org/10.1093/ageing/25.2.113.

17. Javier F, Sánchez M, Gil P. Valoración funcional en la demencia grave, vol. 41; 2006. p. 43-9.

18. Byrne LM, Wilson PM, Bucks RS, Hughes AO, Wilcock GK. The sensitivity to change over time of the Bristol Activities of Daily Living Scale in Alzheimer's disease. Int J Geriatr Psychiatry. 2000;15(7):656-61.

19. Peña-Casanova J, Aguilar M, Bertran-Serra I, Santacruz P, Hernández G, Insa R, Pujol A, Sol JM, Blesa R. [Normalization of cognitive and functional assessment instruments for dementia (NORMACODEM) (I): objectives, content and population]. Neurologia. 1997;12(2):61-8

20. Buiza C, Navarro A, Díaz-Orueta U, et al. Evaluación breve del estado cognitivo de la demencia en estadios avanzados: resultados preliminares de la validación española del Severe Mini-Mental State Examination. Rev Esp Geriatr Gerontol. 2011;46:131-8. https://doi.org/10.1016/j.regg.2010.09.006.

21. Garre-Olmo J, Planas-Pujol X, López-Pousa S, et al. Cross-cultural adaptation and psychometric validation of a Spanish version of the quality of life in late-stage dementia scale. Qual Life Res. 2010;19:445-53. https://doi.org/10. 1007/s11136-010-9594-8.

22. Badia X, Roset M, Montserrat S, Herdman M, Segura A. The Spanish version of EuroQol: a description and its applications. European Quality of Life scale]. Med Clin (Barc). 1999:112 Suppl 1:79-85.

23. Boada $\mathrm{M}$, Cejudo J, Tàrraga $\mathrm{L}$, et al. Neuropsychiatric Inventory Questionnaire (NPI-Q): validación española de una forma abreviada del Neuropsychiatric Inventory (NPI). Neurología. 2002;17(6):317-23.

24. Darbà J, Kaskens L, Lacey L. Relationship between global severity of patients with Alzheimer's disease and costs of care in Spain; results from the codependence study in Spain. Eur J Health Econ. 2015;16:895-905. https://doi. org/10.1007/s10198-014-0642-0.

25. Martín M, Salvadó I, Nadal S, Miji LC, Rico JM, Lanz P, et al. Adaptación para nuestro medio de la Escala de Sobrecarga del Cuidador (Caregiver Burden Interview) de Zarit. Rev Gerontol. 1996;6:338-46.

26. Raina P, Santaguida P, Ismaila A, et al. Effectiveness of cholinesterase inhibitors and Memantine for treating dementia: evidence review for a clinical practice guideline. Ann Intern Med. 2008;148:379. https://doi.org/10. 7326/0003-4819-148-5-200803040-00009.

27. Brodaty $\mathrm{H}$, Connors $\mathrm{MH}$, Xu J, et al. Predictors of institutionalization in dementia: a three year longitudinal study. J Alzheimers Dis Published Online First: 2014. https://doi.org/10.3233/JAD-131850.

28. Annear MJ, Toye C, Mclnerney F, et al. What should we know about dementia in the 21st century? A Delphi consensus study. BMC Geriatr. 2015; 15:5. https://doi.org/10.1186/s12877-015-0008-1.

29. Wübker A, Zwakhalen SMG, Challis D, et al. Costs of care for people with dementia just before and after nursing home placement: primary data from eight European countries. Eur J Health Econ Published Online First. 2015. https://doi.org/10.1007/s10198-014-0620-6

30. Wimo A. Long-term effects of Alzheimer's disease treatment. Lancet Neurol. 2015. https://doi.org/10.1016/S1474-4422(15)00302-6.

Ready to submit your research? Choose BMC and benefit from:

- fast, convenient online submission

- thorough peer review by experienced researchers in your field

- rapid publication on acceptance

- support for research data, including large and complex data types

- gold Open Access which fosters wider collaboration and increased citations

- maximum visibility for your research: over $100 \mathrm{M}$ website views per year

At BMC, research is always in progress.

Learn more biomedcentral.com/submissions 